\title{
SUPPORT FOR TEACHERS TO REDUCE EARLY SCHOOL LEAVING
}

\author{
Kristīne Liepiṇa', Lūcija Rutka² \\ ${ }^{1}$ State Education Quality Service, Latvia \\ 2 RISEBA University of Applied Science, Latvia
}

\begin{abstract}
The early school leaving is an important topic in many countries. High early school leaving rates have many costs to individuals and society as a whole (Andrei et al., 2011). State Education Quality Service in Latvia implements European Social Fund Project No. 8.3.4.0/16/I/001 "Support for reducing early school leaving" to reduce the number of children and young people leaving school. The project promotes the creation of a sustainable cooperation system between the municipality, school, educators and parents to identify children and young people at risk of early school leaving and provide them with personalized support.

Teacher has great influence on students' educational decisions (Dunn et al., 2004). The way teachers see themselves as professionals and how they compose their identities in schools is important factor in preventing early school leaving. In order for the teachers to feel confident in their contribution and possible positive solution to the problem, they must have knowledge of the problem and effective solutions. According to the Project teachers are given the opportunity to professionally develop and strengthen their skills for working with young people.

The aim of the study is to study the role of a teacher in reducing early school leaving and to reveal the necessary forms of support for the performance of pedagogical activity. Data for this study came from a survey and focus group discussion. 815 teachers participated in the study. Analysis of the data reveals that there are several dimensions in the role of the teacher in reducing early school leaving: creating a favorable and safe learning environment, promoting cooperation with parents and colleagues, improving one's pedagogical competence, helping students to identify and solve learning and interpersonal problems, and revealing their mental and physical potential. The research results show main areas of professional development of teachers: sharing experience with colleagues and learning from each other, learning student's individuality at a greater extent, diversification of teaching methods, promoting personal development.
\end{abstract}

Keywords: early school leaving, learning environment, prevention, professional development of teacher, teacher efficacy. 


\section{Introduction}

Reducing the high levels of early school leaving is one of the main challenges facing most of European education systems (European Commission, 2011). Latvia faces challenges in providing equal educational opportunities in all geographic areas, due to significant demographic changes in recent years, driven by substantial emigration and urbanisation. Evidence shows that resulting complications include providing enough places for early childhood education and care in urban areas, improving outcomes for rural students (who as a group have shown lower performance and higher early school leaving rates than their urban counterparts) and optimising the school network to align with the new demographic reality (OECD, 2017). The students' early school leaving is an important topic in many countries. High early school leaving rates have many costs to individuals and society as a whole (Andrei et al., 2011). Early school leaving is an issue that impacts more than just the student who makes this decision; it also affects his or her family, the community, and society as a whole (Christle et al., 2007). There is an overwhelming amount of research that explains the harsh realities of how early school leaving negatively impacts students for the rest of their life. For instance, students who drop out report higher levels of unemployment, lower wages, and greater health concerns later in life (Christle et al., 2007). In the school year $2017 / 2018$, around $7.5 \%$ of students dropped out from upper secondary education, and 19\% from upper secondary vocational education (Latvian Ministry of Economics, 2018).

State Education Quality Service in Latvia implements European Social Fund Project No. 8.3.4.0/16/I/001 "Support for reducing early school leaving" to reduce the number of children and young people leaving school and not completing school. It is planned to involve at least $80 \%$ of municipalities, covering 614 general and vocational education institutions. The project promotes the creation of a sustainable cooperation system between the municipality, school, educators and parents to identify children and young people at risk of early school leaving and provide them with personalized support. Teachers are given the opportunity to professionally develop and strengthen their skills for working with young people.

A wide variety of variables have been found to correlate with early school leaving, and identifying students as high risk has become a crucial topic in efforts to reduce the school leaving rate. A student's decision to leave the school is not a sudden act, but a slow process of disengagement over a period of years. With good research in recent years, it is clear that warning signs of early school leaving are apparent well before students actually leave school, signalling the gathering storm of trouble for some as 
early as the elementary or initial middle grades. Research also shows that most students at risk of falling off track could graduate if they were provided with the appropriate supports early enough and those supports were sustained. School staff need to be prepared to prevent and deal with this issue and schools should take actions to intervene in early school leaving prevention.

\section{Effective Teacher}

School as a system and teacher has great influence on students' educational decisions (Dunn et al., 2004). Teachers are looked upon as the individuals who can help to bring about positive changes in the lives of people. They are seen as natural leaders who can give advice on various affairs in the community. But the problem is that teachers do not see themselves as powerful. This suggests the importance of teachers believing in their effectiveness at helping their students persist in school, no matter what obstacles the students may be facing. If teachers who work with at-risk students on a daily basis do not realize the importance of their interactions with students and the positive effect they can have on student educational outcomes, schools' prevention efforts may be less effective.

The way teachers see themselves as professionals and how they compose their identities in schools is important factor in preventing early school leaving. The role of the teacher and its management style is highly important and essential for succeeding in educational objectives of students in proportion of today world. Many researches show (Göncz, 2017; Levine, 2017; Trapanese, 2017; Warren, 2016) that differences in teacher effectiveness have a profound impact on student learning and have been shown to effect student performance for several years. Teachers with low self-efficacy have a negative effect on student performance (Kilday et al., 2016). However, teachers with high self-efficacy positively influence student accomplishments (Mojavezi \& Tamiz, 2012).

The concept of self-efficacy is founded in Bandura's social cognitive theory: it is a belief in one's capability to organize and execute the course of action required to produce given attainment (Bandura, 1977). Other scholars have also attempted to unfold its various aspects. Tschannen et al. (1998) discussed self-efficacy as the teachers' belief in their capacity to organize and execute the course of actions to accomplish a specific teaching task in a particular context. According to Maddux (2002), it is a perception of what can be done with one's skill.

William H. Kitchen (2014) gives a view of education as a process that liberayes through the guidance and leadership of authority. An essential task involved in effective teaching is the need for a teacher to establish and maintain authority over the organisation and management of pupils' 
learning (Khany \& Tarlani-Alibadi, 2016; Warren, 2016). A literature review on early school leaving in education identifies the need to update teachers' skills in order to improve their abilities in teaching and communicating (Cerda-Navarro et al., 2017). This could help teachers better understand the cultural and linguistic diversity of students and how diversity relates to early school leaving, as well as improve communication between teachers, students and families. Teachers are the key actors to motivate students to learn, therefore teachers shall be equipped and supported to increase their self-efficacy and professional commitment.

In order for the teachers to feel confident in their contribution and possible positive solution to the problem, they must have knowledge of the problem and effective solutions. Research shows that teacher education improves teachers' sense of self-efficacy and that they are more competent in dealing with problem situations related to early school leaving prevention and are confident in their co-responsibility, significantly less likely to experience burnout (Geissler, 2015). Teacher training is a highly emphasized component in the support system for teachers. Reyes et al. (2012) as mentioned in Geissler (2015) research does indicate that student outcomes in response to universal social and emotional learning programs is related to the quality of teachers as program implementers, and that teachers who attend more trainings were rated as higher quality implementers.

Reduction of early school leaving is the target of the prevention/intervention program in context of European Social Fund Project No. 8.3.4.0/ 16/I/001 "Support for reducing early school leaving" and teachers receive trainings in order to support students into the school curriculum. Teachers are provided with the opportunity to develop professionally and to strengthen their skills in working with learners. Methodological tools have been developed within the framework of the project.

\section{Method}

This practical research has been completed within the framework of the European Social Fund Project No. 8.3.4.0/16/I/001 "Support for reducing early school leaving" implemented by the State Education Quality Service in Latvia. The teachers have been offered three programs for improving their professional competence:

1. "Supportive Learning Environment - Educational Resource" altogether 326 teachers participated.

2. "Teacher's Competence and Effectiveness in Modern Pedagogical Circumstances", altogether 441 teachers participated.

3. "Individual and Group Consulting - Professional Activity in Education" altogether 351 teachers participated. 
Altogether 1118 teachers from all regions of Latvia participated in these three programs from June 2019 to December 2020, but altogether 815 teachers completed the survey and involved in the focus group discussions.

Research methods:

1. Teachers survey.

2. Focus group discussions.

3. Mathematically statistical data processing (the $\operatorname{IBM}^{\circledR}$ SPSS $^{\circledR}$ software platform).

The focus group discussions were held within the program for professional development, but the surveys were completed at the end of the lessons. The surveys from June 2019 to March 2020 were completed in paper format. However, due to the Covid-19 restrictions as of March 2020 to December 2020, these surveys had been done electronically, and have been sent to the course manager's e-mail address as soon as the class has been finished. The educators of Latvian primary and secondary schools as well as vocational education institutions took part in these surveys. The number of the respondents, which is 815 , has been made up by educators who participated in the courses and filled in the surveys as well as took part in the focus group discussion.

\section{Results}

The practical research showed the functions of an educator in perspective of teachers regarding the reduction of early school leaving and the required supportive measures to be used by teachers in modern educational process.

During the focus group discussions, respondents, while analysing the skills, competences a teacher must have, and the role of a teacher on the whole, currently have highlighted that, particularly over the Covid-19 restrictions period, it was very essential to be able to share experience and learn from each other (see Figure 1).

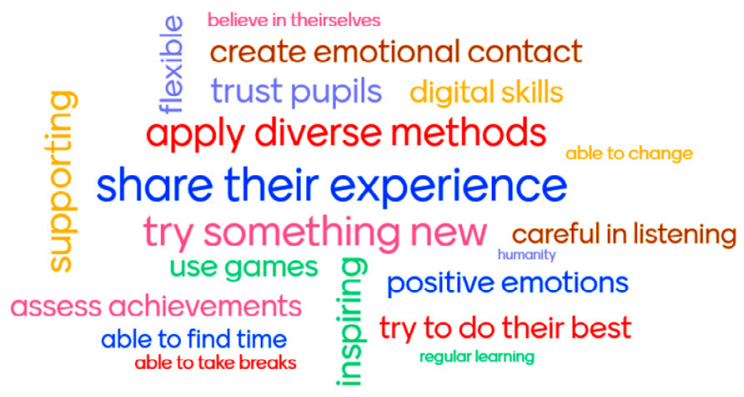

Figure 1. The basic skills of a modern teacher in perspective of educators 
This creates the sense of community and provides a potential for new solutions, especially in reducing early school leaving rate. The teachers pointed out that it was important to try new approaches to cooperation with both students and parents, and apply diverse teaching methods, including various games, to create an emotional connection with students, to inspire and support them as well as be able to assess achievements by students and provide feedback for them as well as trust them. The respondents said the teacher should be able to experience positive emotions, to learn on regular basis, to try to do their best, be flexible, and have digital skills.

Having been asked about the predominant problems identified by teachers in working with students, who form the risk group of early school leaving, altogether $31 \%$ respondents named the internal feeling of powerlessness caused to teachers, meanwhile, $26 \%$ respondents said this was the lack of motivation for students, $13 \%$ named the uninterested parents, and $11 \%$ respondents named different levels of students' knowledge and weak time management and self-regulation. 8\% answered that this was students' material issues, which could be seen as the lack of computers, cameras, microphones and the lack of Internet connection (see Figure 2).

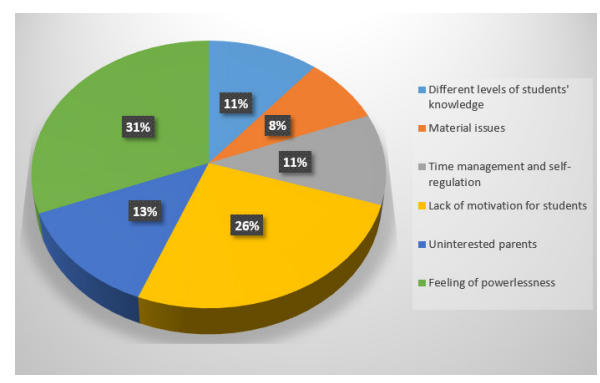

Figure 2. Predominant issues in teacher's work

During the focus group discussion, the teachers stressed the key functions of a teacher in pedagogical process both in face-to-face learning and distance-learning:

- Creating favorable and safe learning environment.

- Promoting cooperation between parents and colleagues.

- Improving one's pedagogical competence.

- Providing support for students to identify and solve learning and interpersonal problems, to reveal their mental and physical potential.

- Promotion of students' learning skills, including the improvement of digital skills.

- Career counselling and help in choosing their occupation.

In the survey for teachers, they were asked to indicate the areas and types of their professional development All the answers by the teachers can 
be divided into four groups, which can be characterised by further professional development areas or dimensions: 1) sharing experience with colleagues, 2) studying student's individuality, 3) diversification of teaching methods, 4) promoting personal development. Each professional development area named by teachers includes definite subdivisions (see Figure 3).

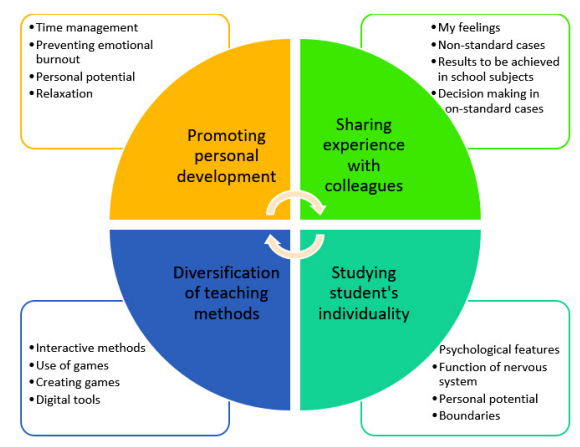

Figure 3. Areas of teachers' professional development

The respondents indicated that they would like to cooperate at a greater extent and learn from each other, speaking of their feelings, decision making in non-standard cases and an option to better achieve learning results. The teachers also pointed out that they wished to study their students' personality and individuality at a greater extent, by learning the nervous system function, the correlation of students' temperament, emotions, and cognitive processes with the learning achievements and learning peculiarities. The respondents wished to learn new teaching methods, especially in digital environment that would promote students' involvement in learning and achieving learning results. Also, the teachers would like to learn time management and manage and control their emotions as well as learn their mental potential and new relaxation techniques.

\section{Discussion}

In order to reduce students' early school leaving, identify children and young people at risk of early school leaving and to provide them with personalized support, the personality of a teacher and their competences play a very important role. The results of this practical research showed that Latvian educators are able to define the key pedagogical issues, are aware of their professional needs, and understand the mechanism for preventing early school leaving risks - i. e., creating interprofessional teams involving colleagues, school staff, parents, and professionals of other industries in addressing various pedagogical issues and promoting their professional and 
personal development. The above said facts are in line with the conclusions of the latest scientific studies (Muceniece, 2020), which outline the emotional involvement of both educators and parents, the development of supportive culture for communication, constructive, positive relations and providing psychological support.

The study results show that teachers have come to the conclusion that they have to learn on a regular basis and develop their personality, to improve their specific skills and competences, related to providing support for students who are at a risk of leaving school and forming a risk group (see Figure 3). In this regard, several issues arise, and the areas of the further research are identified, which are as follows:

How to identify students who are not forming a risk group yet, but there are certain signs related to their behavior, showing that these students might leave school early?

Which specific skills should a teacher have in order to identify these signs and provide targeted, timely support, involving parents, colleagues, and potential stakeholders?

How to encourage students to involve in distance-learning process?

During further research, it would be important to study signs of students behavior, showing that they might form a risk group of early school leaving as well as the types of professional development courses and training programs that might facilitate professional efficacy of teachers in the related area. Another important area of research is promoting students engagement in learning in digital environment related to the digital competences and personal traits of character of a teacher.

\section{Conclusions}

- The functions of a teacher for reducing early school leaving are creating favorable and safe learning environment, promoting cooperation with parents and colleagues, improving their pedagogical competence, providing help for a student to identify and solve learning and interpersonal problems as well as reveal their mental and physical potential.

- The key skills of a modern teacher are the usage of a variety of methods for their work, sharing their professional experience, creativity as well as such traits of character as trust, responsibility, support, and inspiration.

- The research results show 4 main areas of professional development of teachers: 1) Sharing experience with colleagues and learning from each other. 2) Learning student's individuality at a greater extent. 3) Diversification of teaching methods. 4) Promoting personal development. 
- The areas of the further research are related to the development of the teacher's skills to promote students' involvement in learning in digital environment and timely recognition of signs typical of early school leaving before a student has not come to the risk group.

\section{References}

Andrei, T., Oancea, B. (2011). Characteristics and causes of school dropout in the countries of the European Union. Procedia - Social and Behavioral Sciences, 28, 328-332. https://www.researchgate.net/publication/233765093

Bandura, A. (1977). Self-efficacy: Toward a unifying theory of behavioral change. Psychological Review, 84(2), 191-195. https://doi.org/10.1037/0033-295X.84.2.191

Cerda-Navarro, A., Sureda-Negre, J. \& Comas-Forgas, R. (2017). Recommendations for confronting vocational education dropout: a literature review. Empirical Research in Vocational Education and Training, 9(1). https://doi.org/10.1186/s40461-017-0061-4

Christle, C. A., Jolivette, K., \& Nelson, M. (2007). School characteristics related to high school dropout rates. Remedial and Special Education, 28, 325-329. https://www. researchgate.net/publication/249835363

Dunn, C., Chambers, D., \& Rabren, K. (2004). Variables affecting students' decisions to drop out of school. Remedial and Special Education, 25, 314-323. https://journals. sagepub.com/doi/10.1177/07419325040250050501

European Commission (2011). Tackling early school leaving: A key contribution to the Europe 2020 Agenda. https://eurlex.europa.eu/LexUriServ/LexUriServ.do?uri= COM:2011:0018:FIN:EN:PDF

Göncz, L. (2017). Teacher personality: a review of psychological research and guidelines for a more comprehensive theory in educational psychology. Open Review of Educational Research, 4(1), 75-95. https://doi.org/10.1080/23265507.2017.1339572

Geissler, K. L. (2015). The relationship between teacher training, perceptions of school violence, and burnout. CUNY Academic Works. 330. https://academicworks.cuny.edu/ gc_etds/560/

Khany, Tarlani-Aliabadi (2016). Studying power relations in an academic setting: Teachers' and students' perceptions of EAP classes in Iran. Journal of English for Academical Purposes, 21, 72-85. https://daneshyari.com/article/preview/360163.pdf

Kilday, J. E., Lenser, M. L., \& Miller, A. D. (2016). Considering students in teachers' selfefficacy: Examination of a scale for student - oriented teaching. Teaching and Teacher Education, 56, 61-71. https://doi.org/10.1016/j.tate.2016.01.025

Kitchen, W. H. (2014). Authority and the teacher. London: Bloomsbury Academic.

Latvian Ministry of Economics (2018). Informative report on medium and long-term labor market forecasts. https://www.em.gov.lv/en/informative-report-medium-and-long-termlabour-market-forecasts

Levine, G. (2017). Effective Teacher Characteristics: Future Teachers' Voices. NERA Conference Proceedings 2017. 5. https://opencommons.uconn.edu/nera-2017/5

Maddux, J. E. (2002). Self-efficacy: The power of believing you can. In C. R. Snyder, \& S. J. Lopez (Eds.), Handbook of Positive Psychology (pp. 277-287). Oxford University Press 
Mojavezi, A., Tamiz, M.P. (2012). The impact of teacher self-efficacy on the students' motivation and achievement. Theory \& Practice in Language Studies, 2(3), 325-330. http://www.academypublication.com/issues/past/tpls/vol02/03/08.pdf

Muceniece G. (2020). Promoting Teacher's Well-Being with Help of Supervision. // Master's Thesis. Riga: RISEBA University, p. 105-107

OECD (2017). Education policy outlook Latvia. https://www.oecd.org/education/ Education-Policy-Outlook-Country-Profile-Latvia.pdf

Trapanese, E. M. (2017). Helping teachers become leaders. The Education Digest, 83(3), 37-39.

Tschannen, M, Hoy, A. W., \& Hoy, W. K. (1998). Teacher efficacy: Its meaning and measure. Review of Educational Research, 68(2), 202-248. https://doi.org/10.3102/ 00346543068002202

Warren, L. L. (2016). Viewing teachers as leaders without being administrators. Education, 136(4), 508-514. 